\title{
Commentary
}

\section{Neighbourhood effects research at a crossroads. Ten challenges for future research Introduction}

Over the last twenty-five years a vast body of literature has been published on neighbourhood effects: the idea that living in more disadvantaged neighbourhoods has a negative effect on residents' life chances over and above the effect of their individual characteristics. Starting with the work by Wilson (1987), neighbourhood effects have now been reported on outcomes such as educational achievement, school dropout rates, deviant behaviour, social exclusion, health, transition rates from welfare to work, and social and occupational mobility (see van Ham et al, 2012a). Google Scholar returns more than 17000 hits on 'neighbourhood effects' and the volume of work is still growing.

The concept of neighbourhood effects - as an independent residential, economic, social, or environment effect - is academically intriguing, and has been embraced by policy makers. Area-based policies aimed at socially mixing neighbourhood populations through mixed-tenure policies are seen as a solution to create a more diverse socioeconomic mix in neighbourhoods, removing the potential of negative neighbourhood effects (Musterd and Andersson, 2005). Mixed housing strategies are stated explicitly by many governments including those in the Netherlands, the United Kingdom, Germany, France, Finland, and Sweden (Musterd, 2002).

The volume of work on neighbourhood effects not only reflects academic and policy interest in this topic, but also the fact that we are still no closer to answering the question of how important neighbourhood effects really are (van Ham et al, 2012a). Many existing studies fail to convincingly show real causal neighbourhood effects, because they ignore, or do not adequately deal with neighbourhood selection effects (Durlauf, 2004; van Ham and Manley, 2010). This leaves the impression that neighbourhood effects are important, while in reality these studies might just show correlations between individual outcomes and neighbourhood characteristics (Cheshire, 2007). Despite the ever-growing body of neighbourhood effects research, we do not know enough about the causal mechanisms which may produce them, their relative importance in shaping an individual's life chances, the circumstances or conditions under which they are most important, or the most effective policy responses (van Ham et al, 2012a).

According to Small and Feldman (2012), neighbourhood effects research is at a crossroads since current empirical and theoretical approaches to the topic do not seem to be moving the debate forward. It is at this crossroads where this paper offers its contribution, summarised into ten challenges for future research.

\section{Belief in neighbourhood effects}

The belief in neighbourhood effects among policy makers and the general public is strong and persistent, and fuelled by media attention. The beliefs in policy circles can be illustrated by a quote from the UK Office of the Deputy Prime Minister: "People living in deprived neighbourhoods are less likely to work, more likely to be poor and have lower life expectancy ... . Living in a deprived area adversely affects individuals' life chances over and above what would be predicted by their personal circumstances and characteristics" (ODPM, 2005, page 6). The quote illustrates the uncritical adoption of the neighbourhood effects discourse and accepting neighbourhood effects as a fact. 
Media attention fuels the belief in neighbourhood effects. The Channel 4 television program Best and Worst Places to Live uses measurements of crime, environment, lifestyle, health, education, and employment to produce a ranking of places in the United Kingdom. The presenters often suggest that living in, or moving to (!) some of the worst areas will cause you to suffer from health problems, and shorten your life, while moving to some of the best places will help you to live longer (http://www.channel4.com/). Purposefully or not, the presenters are suggesting that there is a causal link between moving to certain places and a change in individual outcome such as life expectancy.

Whilst the Channel 4 programme is presented as light hearted entertainment, more serious media also fuel the belief in neighbourhood effects. In 2011 the BBC broadcast the programme This is Britain with Andrew Marr (BBC2, 25 March 2011). In the programme two well-respected academics try to present a highly complex set of arguments about how neighbourhood and life expectancy are linked, using Glasgow as an example.

Danny Dorling: "What is the kind of life expectancy of people living right where we are now, and what is it like just around here?"

Rich Mitchell: “Ok, right right here, for a man, it's 79 years at birth. Just down the street there you rise to 80 years. If you were to go that way maybe about half a mile, err, you'd drop about 5 years, about another half a mile on you'd drop 15 years $[\ldots]$ if you carry on in that direction you go through some of the, kind of, poorer parts of the city where things get really bad"

Danny Dorling: "It's stunning isn't it?"

Rich Mitchell: “Extraordinary, and that's the power of neighbourhood, err, because neighbourhood is the place in which, you know, your social and economic life come together to determine things"

Andrew Marr: "In order to understand how you can drop 15 years of your life just by crossing a few streets, imagine a ..."

The problem here is not the discussion that the academics have (although they do suggest that there is a causal - 'to determine things'—relationship), but the voiceover by the presenter, who infers that simply by moving to the other side of town an individual will lose years of their life expectancy. This BBC programme was watched by 1.75 million people, ${ }^{(1)}$ which is more people than will ever read even the best academic papers.

The above examples of neighbourhood effects as a folk concept offer a gross oversimplification of the evidence in the academic literature and suggest that the neighbourhood effects discourse is unchallenged and unproblematic. This is dangerous: whilst neighbourhood effects remain a popular undisputed 'truth' in the public sphere, a careful examination of the academic literature reveals a very different picture (see next section). Also, there is a painfully ironic consequence of the style of presentation in This is Britain with Andrew Marr as it reinforces the very inequalities that the programme sought to expose. Using stereotypical and explicit imagery of deprived neighbourhoods the programme pathologises poor neighbourhoods (see also Bauder, 2002), something commentators have described as 'poverty porn' (Mooney and Hancock, 2010). Making a link between academic research and the policy and media debate is crucial because "[i]f public discourse uncritically embraces this essentialist conception of neighbourhood culture, then it sanctions policies and social conventions that enforce cultural exclusion and facilitate acculturation" (Bauder, 2002, page 85).

${ }^{(1)}$ BARB—Broadcasters' Audience Research Board (http://www.barb.co.uk). 


\section{Empirical evidence of neighbourhood effects}

There are several papers and edited books which give overviews of the development and current state of the neighbourhood effects literature (see for a review Durlauf, 2004; Ellen and Turner, 1997; Galster, 2002; van Ham et al, 2012a; 2012b) and there is no need to repeat these here as this commentary focuses on the future direction of neighbourhood effects research. However, it is useful to give a short overview of the types of studies available and the type of results they yield and the problems associated with these studies and approaches.

There is a substantial divide in the neighbourhood effects literature between qualitative and quantitative studies. Qualitative studies, focusing on the experiences and perceptions of residents, generally show stronger and more consistent support in favour of the neighbourhood effects hypothesis than quantitative studies. For instance, using qualitative techniques, neighbourhood effects of poor reputations of neighbourhoods have been repeatedly identified on employment outcomes (see Atkinson and Kintrea, 2001), and on social processes, including social networks, acting on other socioeconomic outcomes of residents living in deprived neighbourhoods (Pinkster, 2009).

Quantitative studies have been much less consistent in their outcomes, although the majority of nonexperimental observational studies find support for the neighbourhood effects hypothesis. A growing body of critical empirical literature argues that most of these studies show only correlations between neighbourhood characteristics and individual outcomes, which are caused by selection effects, and are no real causal neighbourhood effects (eg, Bolster et al, 2007; Cheshire, 2007; Oreopoulos, 2003; van Ham and Manley, 2010). The problem is simply that often the individual characteristic measured as the dependent variable (for example, income) is responsible for people selecting into deprived neighbourhoods in the first place. As a consequence, (a large) part of the correlation between the dependent variable and neighbourhood characteristics is caused by the neighbourhood selection mechanism. This causes serious bias in the estimation of neighbourhood effects. Durlauf (2004) reports that even the gold standard quasi-experimental studies such as the Gautreaux and Moving to Opportunity programmes (Katz et al, 2001; Rosenbaum, 1995) or randomised education studies (see Leventhal and Brooks-Gunn, 2004) find little impact of neighbourhood characteristics on adults' outcomes. But many of these studies are not bias free either (see DeLuca et al, 2012).

\section{Ten challenges for neighbourhood effects research}

In the remainder of this paper we provide a set of ten challenges that we think will give new direction to the neighbourhood effects debate in the next decade. The presentation of these challenges is timely as Western governments seem to have lost their interest in deprived neighbourhoods and the austerity measures being rolled out in many countries will hit individuals in deprived neighbourhoods hardest. It is therefore ever more important to better understand how living in such neighbourhoods affects individual outcomes.

The first challenge is that future work should concentrate on explaining the 'blackbox' of the 'neighbourhood effect' by deriving and testing clear hypotheses on causal neighbourhood effect mechanisms. Currently, most quantitative studies simply identify statistically significant correlations between individual outcomes and neighbourhood characteristics, without explicitly identifying specific causal mechanisms. Galster (2012) has summarised fifteen potential causal pathways which need to be considered in four categories: social-interactive mechanisms (social contagion, collective socialisation, social networks, social cohesion and control, competition, relative deprivation, and parental mediation); environmental mechanisms (exposure to violence, physical surroundings, and toxic exposure); geographical mechanisms (spatial mismatch of jobs and workers and a lack 
of quality public services); and institutional mechanisms (stigmatisation, local institutional resources, and local market actors).

The second challenge is that studies should explicitly investigate the relationship between neighbourhood context and individual outcomes. According to Galster (2012), the ultimate goal of neighbourhood effects research is not only to identify which mechanisms are responsible for neighbourhood effects, but also to ascertain quantitatively their relative contributions to the outcome of interest. He uses the pharmacological metaphor of 'dosageresponse' to understand how the theoretical mechanisms could be causally linked to individual outcomes. He formulates seventeen questions regarding the composition of the neighbourhood dosage, the administration of the neighbourhood dosage, and the neighbourhood dosageresponse relationship which need to be answered to fully understand how the neighbourhood context affects residents. Neighbourhood residents can be exposed to a certain composition of mechanisms, over a certain time, with a certain frequency, and intensity. The relationship between the 'dosage' of neighbourhood to an individual and certain outcomes may be nonlinear (thresholds), be temporary or long-lasting, take time to have an effect, and have an effect only in combination with other factors.

The third challenge is to broaden the range of dependent variables under study to 'softer' outcome variables. Arguably, the range of outcome variables used in studies of neighbourhood effects is already very large, reflecting the interdisciplinary nature of the neighbourhood effects debate. However, the majority of these measures are all relatively 'hard' and normative indicators which are easy to quantify. Recently, countries like France and the UK have begun to attempt to quantify general well-being (happiness) as a valuable complementary measure for the evaluation of social progress (Nowok et al, 2013) and to develop policy responses. So in our focus on, for example, individual income, we should not forget to ask the question whether people are happy where they live, regardless of their income or employment status.

The fourth challenge is to move away from single point-in-time measures of neighbourhood characteristics and to take into account people's neighbourhood histories. Despite a growing body of literature on neighbourhood effects, a crucial dimension of neighbourhood effects is largely overlooked: the temporal dimension (Quillian, 2003; Sharkey and Elwert, 2011). Most studies of neighbourhood effects investigate the instantaneous effects of single pointin-time measurements of neighbourhood environments on individual outcomes. However, it has repeatedly been suggested that most theories of neighbourhood effects assume medium to long-term exposure to poverty neighbourhoods for there to be an effect (Galster, 2012; Hedman et al, 2012; Musterd et al, 2012; van Ham et al, 2012c).

The fifth challenge is to consider the possibility of intergenerational neighbourhood effects. The vast majority of the neighbourhood effects literature has investigated the effects of intragenerational inequalities, while little attention has been paid to intergenerational inequalities. This is surprising given the attention to intergenerational social mobility in especially the sociological literature, and the suggestion that it is becoming increasingly difficult for individuals born in lower social classes to move upwards through their life course (Blanden et al, 2005). This lack of upward mobility might also have a spatial dimension. The few papers which studied how neighbourhood disadvantage can be transmitted through generations found evidence that the parental neighbourhood impacts on children's outcomes later in life as adults (Hedman et al, 2012; Sharkey and Elwert, 2011).

The sixth challenge is to understand neighbourhood selection and to incorporate neighbourhood selection explicitly in models of neighbourhood effects. Merely controlling for selection using econometric techniques is insufficient as selection is at the heart of understanding why certain households move to certain neighbourhoods while others 
do not (Hedman and van Ham, 2012). The overemphasis on using increasingly complex statistical techniques has hampered our understanding of why certain households move to certain neighbourhoods and how this is related to neighbourhood effects. Instead of treating neighbourhood selection as a nuisance which needs to be controlled away, future work should attempt to incorporate models of neighbourhood selection in models of neighbourhood effects (Manley and van Ham, 2012). To do this, we need a theory of selection bias: what are these unmeasured characteristics which cause people to move to certain neighbourhoods, and also cause people to have a certain income, health, or other outcome?

The seventh challenge is to operationalise neighbourhoods better. There are two main issues here. The first is that many studies use standard administrative units as proxies for neighbourhoods. The problem is that individuals might live at the edge of such a unit and as a consequence the neighbouring unit might be a more relevant spatial context. The solution is to create bespoke individual neighbourhoods for each case in the data, which reduces the risk of creating biased neighbourhood estimates because of boundary effects. The second issue is scale. Many of the causal mechanisms suggested to be behind neighbourhood effects will operate at specific scales which may vary between localities and over time (see Kwan, 2012; Manley et al, 2006). It may even be the case that any one mechanism may operate at different scales in different contexts. Convenience and pragmatism have led to a literature that lifts administrative neighbourhood units 'off the shelf' without asking the question of which scale is the most appropriate for testing the causal mechanism under study. For example, when testing hypotheses on peer-group effects for children, the appropriate spatial scale might be relatively low-level (several streets). But when testing hypotheses on stigma and neighbourhood reputations, larger administrative neighbourhoods might be more appropriate.

The eighth challenge is for neighbourhood effects researchers to broaden their horizon to include other spatial contexts which might matter, in addition to, or in place of the residential neighbourhood. As individual lives are becoming increasingly complex, simply mapping an individual's residential space has become less satisfactory as a means to representing the spatial contexts to which they are exposed. The neighbourhood around an individual's dwelling is not the only important spatial context for interactions: equally important could be the neighbourhood of employment, places of leisure, and places and spaces people travel through during their daily routines. We know that "individuals of different social groups tend to have distinctive activity patterns in space-time" (Kwan, 2012, page 961), and if we are to understand how individuals interact and how these interactions can shape their own outcomes then restricting the analysis to (often poorly) defined residential neighbourhoods might be too limited.

The ninth challenge is to collect better data. Current quantitative neighbourhood effects research attempts to overcome the challenge of selection bias by using increasingly complex econometric and statistical techniques. While these techniques are important, they distract from the fact that the data that are available are too often insufficient to adequately model the selection mechanisms themselves. As observed by Rubin (2008), there are potentially greater gains in terms of casual inference to be made through good study design rather than through complex statistical modelling techniques. This may mean that neighbourhood effects researchers need to make more use of bespoke data, collected primarily for advancing the understanding of the effect of neighbourhood context on individual lives.

The tenth and final challenge is to combine qualitative and quantitative methods into one research design (Small and Feldman, 2012). Quantitative analysis of large-scale longitudinal data enriched with contextual data is crucial in testing the generalisability of causal mechanisms, but the 'why question' can never be answered quantitatively and therefore qualitative work is needed that will bring better understandings of the processes 
that underlie these mechanisms. Developing ways to integrate in a single research design the broad generalisations of the quantitative work in establishing if and how inequalities may matter with qualitative investigations of why those patterns occur will advance the field much further than the separated dialogue that we current experience (DeLuca et al, 2012; Small and Feldman, 2012).

Maarten van Ham

Delft University of Technology, OTB Research Institute for the Built Environment, PO Box 5030, 2600 GA Delft, The Netherlands and University of St Andrews, UK and IZA Institute of Labor, Germany; e-mail: m.vanham@tudelft.nl

David Manley

University of Bristol, School of Geographical Sciences, University Road, Clifton, Bristol, BS8 1SS, United Kingdom; e-mail: d.manley@bristol.ac.uk

Acknowledgements. Many of the ideas presented in this commentary were derived from an ESRC Seminar Series: Challenges in neighbourhood effects research: does it really matter where you live and what are the implications for policy (RES-451-26-0704). The authors would like to thank the presenters and participants for their contributions (see www.neighbourhoodeffects.org). Financial support from the EU (NBHCHOICE Career Integration Grant under FP7-PEOPLE-2011-CIG) is also gratefully acknowledged.

\section{References}

Atkinson R, Kintrea K, 2001, "Disentangling area effects: evidence from deprived and non-deprived neighbourhoods" Urban Studies 38 2277-2298

Bauder H, 2002, "Neighbourhood effects and cultural exclusion" Urban Studies 39 85-93

BBC, 2011 This is Britain with Andrew Marr BBC2, 25 March

Blanden J P, Gregg P, Machin S, 2005 Intergenerational Mobility in Europe and North America: Report for the Sutton Trust Centre for Economic Performance, London

Bolster A, Burgess S, Johnston R, Jones K, Propper C, Sarker S, 2007, "Neighbourhoods, households and income dynamics: a semi-parametric investigation of neighbourhood effects" Journal of Economic Geography 7 1-38

Channel 4, 2011 Best and Worst Places to Live http://www.channel4.com/

Cheshire P, 2007 Are Mixed Communities the Answer to Segregation and Poverty? (Joseph Rowntree Foundation, York)

DeLuca S, Duncan G J, Keels M, Mendenhall R, 2012, "The notable and the null: using mixed methods to understand the diverse impacts of residential mobility programs", in Neighbourhood Effects Research: New Perspectives Eds M van Ham, D Manley, N Bailey, L Simpson, D Maclennan (Springer, Dordrecht) pp . 195-224

Durlauf S N, 2004, "Neighbourhood effects", in Handbook of Regional and Urban Economics. Volume 4 Cities and Geography Eds J V Henderson, J F Thisse (Elsevier, Amsterdam) pp 2173-2242

Ellen I G, Turner M A, 1997), "Does neighbourhood matter? Assessing recent evidence" Housing Policy Debate 8 833-866

Galster G, 2002, "An economic efficiency analysis of deconcentrating poverty populations" Journal of Housing Economics 11 303-329

Galster G C, 2012, "The mechanism(s) of neighbourhood effects: theory, evidence, and policy implications", in Neighbourhood Effects Research: New Perspectives Eds M van Ham, D Manley, L Simpson, N Bailey, D Maclennan (Springer, Dordrecht) pp 23-56

Hedman L, van Ham M, 2012, "Understanding neighbourhood effects: selection bias and residential mobility", in Neighbourhood Effects Research: New Perspectives Eds M van Ham, D Manley, N Bailey, L Simpson, D Maclennan (Springer, Dordrecht) pp 79-100

Hedman L, Manley D, van Ham M, Östh J, 2012, "Cumulative exposure to disadvantage and the intergenerational transmission of neighbourhood effects" IZA DP 6794, ftp.iza.org/dp6794.pdf

Katz L, Kling J, Liebman J, 2001, "Moving to opportunity in Boston: early results of a randomized mobility experiment" Quarterly Journal of Economics 116 607-654 
Kwan M P, 2012, "The uncertain geographic context problem" Annals of the Association of American Geographers 102 958-968

Leventhal T, Brooks-Gunn J, 2004, "A randomized study of neighborhood effects on low-income children's educational outcomes" Developmental Psychology 40 488-507

Manley D, van Ham M, 2012, "Neighbourhood effects, housing tenure and individual employment outcomes", in Neighbourhood Effects Research: New Perspectives Eds M van Ham, D Manley, N Bailey, L Simpson, D Maclennan D (Springer, Dordrecht) pp 147-174

Manley D, Flowerdew R, Steel D, 2006, "Scales, levels and processes: studying spatial patterns of British census variables" Computers, Environment and Urban Systems 30 43-160

Mooney G, Hancock L, 2010 "Poverty Porn and the Broken Society" Variant issue 39/40, 14-18

Musterd S, 2002, "Response: mixed housing policy: a European (Dutch) perspective" Housing Studies 17 139-143

Musterd S, Andersson R, 2005, "Housing mix, social mix and social opportunities" Urban Affairs Review 40 761-790

Musterd S, Galster G, Andersson R, 2012, "Temporal dimensions and measurement of neighbourhood effects" Environment and Planning A 44 605-627

Nowok B, van Ham M, Findlay A M, Gayle V, 2013, "Does migration make you happy? A longitudinal study of internal migration and subjective well-being" Environment and Planning A 45 forthcoming

ODPM, 2005 Sustainable Communities: People, Places and Prosperity Cm 6425, Office of the Deputy Prime Minister (The Stationery Office, London)

Oreopoulos P, 2003, "The long-run consequences of living in a poor neighbourhood" The Quarterly Journal of Economics 118 1533-1575

Pinkster F M, 2009 Living in Concentrated Poverty (University of Amsterdam, Amsterdam)

Quillian L, 2003, "How long are exposures to poor neighborhoods? The long-term dynamics of entry and exit from poor neighborhoods" Population Research and Policy Review 22 221-249

Rosebaum J, 1995, "Changing the geography of opportunity by expanding residential choice: lessons from the gatreaux program" Housing Policy Debate 6 231-269

Rubin D B, 2008, "For objective causal inference, design trumps analysis" Annals of Applied Statistics 2 808-840

Sharkey P, Elwert F, 2011, "The legacy of disadvantage: multigenerational neighborhood effects on cognitive ability" American Journal of Sociology 116 1934-1981

Small M, Feldman J, 2012, "Ethnographic evidence, heterogeneity, and neighbourhood effects after moving to opportunity", in Neighbourhood Effects Research: New Perspectives Eds M van Ham, D Manley, L Simpson, N Bailey, D Maclennan (Springer, Dordrecht) pp 57-78

van Ham M, Manley D, 2010, "The effect of neighbourhood housing tenure mix on labour market outcomes: a longitudinal investigation of neighbourhood effects" Journal of Economic Geography 10 257-282

van Ham M, Manley D, Bailey N, Simpson L, Maclennan D (Eds), 2012a Neighbourhood Effects Research: New Perspectives (Springer, Dordrecht)

van Ham M, Manley D, Bailey N, Simpson L, Maclennan D (Eds), 2012b Understanding Neighbourhood Dynamics: New Insights for Neighbourhood Effects Research (Springer, Dordrecht)

van Ham M, Hedman L, Manley D, Coulter R, Östh J, 2012c, "Intergenerational transmission of neighbourhood poverty in Sweden. An innovative analysis of individual neighbourhood histories", IZA DP 6572, ftp.iza.org/dp6572.pdf

Wilson W J, 1987 The Truly Disadvantaged: The Inner City, the Underclass and Public Policy (University of Chicago Press, Chicago, IL) 